\title{
Study of Tribological Behavior of Silicon Carbide Based Aluminum Metal Matrix Composites under Dry and Lubricated Environment
}

\author{
Kalyan Kumar Singh, ${ }^{1}$ Saurabh Singh, ${ }^{1}$ and Anil Kumar Shrivastava ${ }^{2}$ \\ ${ }^{1}$ Department of Mechanical Engineering, Indian School of Mines, Dhanbad 826004, India \\ ${ }^{2}$ Department of Mechanical Engineering, Galgotias College of Engineering \& Technology, Greater Noida 201306, India
}

Correspondence should be addressed to Saurabh Singh; saurabh.091638.bme@gmail.com

Received 17 December 2015; Accepted 11 February 2016

Academic Editor: Guru P. Dinda

Copyright (C) 2016 Kalyan Kumar Singh et al. This is an open access article distributed under the Creative Commons Attribution License, which permits unrestricted use, distribution, and reproduction in any medium, provided the original work is properly cited.

\begin{abstract}
Friction and wear behavior of silicon carbide based aluminum metal matrix composite and aluminum matrix alloy have been studied for sliding speeds of $3.14 \mathrm{~m} / \mathrm{s}$ and $3.77 \mathrm{~m} / \mathrm{s}$ and load range from $10 \mathrm{~N}$ to $30 \mathrm{~N}$ under dry and lubricated environment, respectively. The experiments were performed on pin on disk tribometer (Make: DUCOM). The composite was fabricated by stir casting process and has several challenges like inferior bonds and interfacial reaction products which will deteriorate the mechanical and tribological properties. Therefore, addition of reactive metal like magnesium $(\mathrm{Mg})$ should be done which will lead to reduced solidification shrinkage, lower tendency towards hot tearing, and faster process cycles. Results have revealed that the developed composites have lower coefficient of friction and wear rates when compared with aluminum matrix alloy under dry and lubricated environment. Experimental results show that under dry condition coefficient of friction of both the matrix alloy and the composite decreases with increase in load, whereas it increases with increase in sliding speeds; on the other hand wear rates of both aluminum matrix alloy and the composites increase with increase in load as well as with sliding speeds. FESEM of worn surfaces are also used to understand the wear mechanisms.
\end{abstract}

\section{Introduction}

Aluminum alloy possesses excellent properties like high strength-to-weight ratio, corrosion resistance, good ductility, low density, high thermal conductivity, and so forth, thus making it suitable for wide range of applications in several industries like automobile, aerospace, structural applications, and so forth [1]. In recent times, the uses of high strength aluminum alloys are focused on structural applications in aerospace as well as on general engineering sectors. However aluminum alloys have not been well known for high performance tribological application because of their low hardness, poor wear resistance, and poor weldability. Thus, there is a greater possibility of oscillation since these materials are joined by riveting, bolting, and so forth and due to this it may often lead to sliding wear in dry environmental conditions. Therefore, to overcome this problem reinforcement of particulates, fiber, or whiskers can be used; these reinforcements are very well known for their high-specific strength and uniform distribution [2] which leads to use of metal matrix composites to complete the demand for light weight, high performance, environment friendly, wear and corrosion resistance material. Generally, $\mathrm{Ag}, \mathrm{Al}, \mathrm{Be}, \mathrm{Co}, \mathrm{Cu}, \mathrm{Fe}, \mathrm{Mg}, \mathrm{Ni}$, and $\mathrm{Ti}$ are produced and used as matrices in metal matrix composites. Due to excellent physical, mechanical, and tribological properties and good dimensional stability of aluminum matrix composite it has high commercial application compared to other available metals. The demand for aluminum composite in automobile sector has been increased drastically; this composite is used for the manufacturing of pistons, brake drums, cylinder liners, and pushrods [3, 4]. A commercial Al 7075 aluminum alloy is one of the highest strength aluminum alloys available and is having excellent strength-to-weight ratio and is formed in annealed conditions and subsequently heat treated. But due to its low wear resistance and poor tribological behavior it cannot be widely used; therefore 
TABLE 1: Chemical composition (weight \%) of aluminum matrix alloy (Al 7075).

\begin{tabular}{lcccccccccc}
\hline Material & $\mathrm{Si}$ & $\mathrm{Fe}$ & $\mathrm{Cu}$ & $\mathrm{Cr}$ & $\mathrm{Zn}$ & $\mathrm{Ti}$ & $\mathrm{Mn}$ & $\mathrm{Mg}$ & $\mathrm{Al}$ & $\mathrm{Others}$ \\
\hline Content & Max 0.4 & 0.5 & $1.2-2$ & $0.18-0.28$ & $5.1-6.1$ & 0.2 & 0.3 & $2.1-2.9$ & $87.1-91.4$ & 0.15 \\
\hline
\end{tabular}

reinforcement of particles has been done to improve its tribological properties. There are various particles available which are used for reinforcement such as $\mathrm{B}_{4} \mathrm{C}, \mathrm{SiC}, \mathrm{TiC}$, $\mathrm{B}, \mathrm{C}$, and $\mathrm{Al}_{2} \mathrm{O}_{3}$. With the reinforcement of high modulus ceramics particulates such as silicon carbide $(\mathrm{SiC})$ having properties like more stability and chemical compatibility with aluminum matrix and low cost, wide range of available grade made aluminum alloys are suitable candidate for wider spectrum of applications [5]. The hard reinforcement of silicon carbide particle improved the properties like hardness and wear resistance of composite by acting as load bearing components [6, 7]. Many investigators have studied both parameters, that is, reinforcement size and volume fraction; Aiguo and Rack [8] observed that abrasive wear resistance in unreinforced 7091 alloys is less in comparison with both silicon carbide particle and silicon carbide whiskers. Wear resistance increases and plastic deformation decreases with the increase of reinforcement $[9,10]$. Kwok and Lim [11] observed the size of silicon carbide reinforcement at high speed and suggested that when the particulate size becomes small the wear resistance rapidly deteriorates. Therefore, silicon carbide based aluminum metal matrix composites are mainly preferred for low speed applications; silicon carbide is commonly used among the reinforcement particles like carbides, nitrides, borides, and oxides, because it has several advantages like high melting point, high elastic modules, hardness, good thermal conductivity, high strength, excellent wear resistance, good availability, and low cost. Silicon carbide based aluminum metal matrix composites are widely used in automotive, marine, and other sectors because of its excellent properties such as good fluidity and low coefficient of thermal expansion and its quality depends on chemical composition, melting process, casting process, and solidification rate. As the volume fraction addition of silicon carbide in aluminum alloys increases, the value of ultimate tensile strength (UTS) increases and low degree of porosity is obtained.

There is not much improvement in strength and porosity of material, if the volume fraction of silicon carbide exceeds $10 \%$; therefore in the present analysis $10 \%$ silicon carbide has been added in aluminum alloys as reinforcement. Due to low degree of porosity and uniform distribution of silicon carbide particles there is enhancement in tensile strength of composites and as a result it leads to effective transfer of tensile loads to the uniformly distributed silicon carbide particulates. In silicon carbide based aluminum metal matrix composites, casting properties increased by adding silicon whereas magnesium $(\mathrm{Mg})$ made its heat treatable which greatly influenced the mechanical properties of composites.

There are several manufacturing techniques that are available for particle reinforcement in metal matrix composites such as liquid infiltration, spray decomposition, squeeze casting, compocasting, powder metallurgy, and mechanical alloying. Among all these available methods, stir casting method is attractive method for manufacturing of metal matrix composites (MMCs) because of low cost, near-net shape formation, and wide range of processing applications $[1,5,12]$. The mechanical strength of aluminum metal matrix composites is greatly influenced by particles size reinforcement; if size of particles ranges from micrometer to nanometric scale there is drastic increase in mechanical strength of composites but it will increase chance of agglomeration and particle clustering which will reduce the strength of composites. Therefore, it is important that reinforcement of particles should be homogeneous to achieve the improved properties of composites [13]. In stir casting method, ceramics reinforcement (i.e., silicon carbide) and metal matrix which is melted during casting are mixed homogeneously by mechanical stirrer. Fabrication of aluminum metal matrix composites has several challenges like inferior bonds and interfacial reaction products and it will directly deteriorate the mechanical properties and tribological properties of composites, which make them unsuitable for industrial application. Therefore, to overcome this problem, addition of reactive metal like magnesium has been done and the addition of this metal results in reduced solidification shrinkage, lower tendency towards hot tearing, suppression of segregation, settling or agglomeration, and faster process cycles [12].

Thus by analyzing various parameters and their effects and utilization this experiment was carried out under various environmental conditions to produce a material which can sustain a longer time. Composite fabricated has much better properties as compared with its base alloys (details and validation of which are shown in the experimental analysis). The severity of worn-out surfaces (i.e., wear scars, change of microstructure) was also analyzed using field emission scanning electron microscopes (FESEM).

\section{Experimental Procedure}

2.1. Fabrication of Silicon Carbide Based Aluminum Metal Matrix Composite. The composite was prepared by commercially available aluminum (Al 7075) matrix alloy and silicon carbide (10\% by weight) which is used as reinforcement. The average size of aluminum matrix alloy was 150 microns to 160 microns and that of silicon carbide was 40 microns to 50 microns. In the present investigation, aluminum matrix alloy was chosen as a base matrix since it is having very high tensile strength of about $275 \mathrm{MPa}$. The addition of silicon carbide will enhance the wear resisting property of silicon carbide based aluminum metal matrix composite. The chemical composition of aluminum matrix alloys is presented in Table 1.

2.2. Composite Preparation. In order to achieve high level of mechanical properties of the composite, a good interfacial 
TABLE 2: Chemical composition of silicon carbide based aluminum metal matrix composite.

\begin{tabular}{cccccccccc}
\hline Material & $\mathrm{C}$ & $\mathrm{O}$ & $\mathrm{Mg}$ & $\mathrm{Al}$ & $\mathrm{Si}$ & $\mathrm{Fe}$ & $\mathrm{Ag}$ & $\mathrm{Zn}$ & $\mathrm{Cu}$ \\
\hline Content & 24.27 & 20.61 & 1.13 & 36.43 & 10.62 & 1.96 & 0.84 & 3.34 & 0.80 \\
\hline
\end{tabular}

bonding (wetting) between the dispatched phase and the liquid matrix has to be obtained. Fabrication of composite with discontinuous fiber can be economically done using liquid metallurgy route/technique [10]. Stir casting is a liquid state method which is the simplest and is cost effective to fabricate metal matrix composite. Care was taken to maintain optimum casting parameters of pouring temperature $\left(670^{\circ} \mathrm{C}\right)$ stirring speed of $500 \mathrm{rpm}$, stirring time 20 minutes. The reinforcement was preheated at $600^{\circ} \mathrm{C}$ to the addition in aluminum matrix alloy (Al 7075). To avoid moisture from the particles, preheating of the reinforced particle should be done; otherwise, there is a chance of agglomeration of particulate which occurs due to moisture and gasses present in the particles. Degassing agent (hexachloroethane and magnesium) was used to reduce the gas porosities. The addition of magnesium will also lead to reduced solidification shrinkage, lower tendency towards hot tearing, suppression of segregation, settling or agglomeration, and faster process cycles. The depth of immersion of stirrer was maintained at about two-thirds of the depth of molten metal. The molten metal was then poured into a permanent mould preheated at $300^{\circ} \mathrm{C}$ of $9 \mathrm{~mm}$ diameter and $55 \mathrm{~mm}$ length. Specimen was left for curing and die was released after 6 hours; finally, on the lathe cast specimens were parted out in 2 pieces, that is, $25 \mathrm{~mm}$ length and $8 \mathrm{~mm}$ diameter, respectively. The chemical compositions of silicon carbide based aluminum metal matrix composite are presented in Table 2.

\subsection{Composite and Aluminum Matrix Alloy Testing Procedure.}

The experiment was conducted at room temperature on a pin on disk wear and friction maintaining machine (Make: DUCOM instruments private limited, Bangalore diameter of $165 \mathrm{~mm}$, thickness of $8 \mathrm{~mm}$ and made of material EN31 hardened to $60 \mathrm{HRC}$ ground to $1.6 \mathrm{Ra}$ surface roughness. Figure 1 shows the photographic view of disk). The size of cylindrical specimen which was used for testing is $8 \mathrm{~mm}$ diameter as well as $25 \mathrm{~mm}$ length. Before performing every experiment disk surface was cleaned by rubbing 600-grade Si6 emery paper and washed with acetone. Three different loads, that is, $10 \mathrm{~N}, 20 \mathrm{~N}$, and $30 \mathrm{~N}$, have been selected for wear and friction behavior of specimen with track diameter of $100 \mathrm{~mm}$ and $120 \mathrm{~mm}$ used for both aluminum matrix alloy and silicon carbide based aluminum metal matrix composite. The test duration was 10 minutes at a constant speed of $600 \mathrm{rpm}$ for the entire test in dry and oil lubricated (SAE 20 with kinematic viscosity 25 to 30 centistokes at $50^{\circ} \mathrm{C}$ and oil has been used for lubrication) conditions. For oil lubricated experiments, initially, 2 drops of lubricating oil were placed over sliding surface after that oil was poured at $0.02 \mathrm{~mL} / \mathrm{min}$. All sets of experiments were repeated three times in the same manner for dry and oil lubricated conditions, respectively. Frictional forces and coefficient of friction were measured directly from the machine. For the calculation of wear loss
TABLE 3: Variation of coefficient of friction with load for aluminum matrix alloy and silicon carbide based aluminum metal matrix composite at $V=3.14 \mathrm{~m} / \mathrm{sec}$.

\begin{tabular}{lcc}
\hline $\begin{array}{l}\text { Sliding condition \& } \\
\text { load }\end{array}$ & $\begin{array}{c}\text { COF for } \\
\text { aluminum } \\
\text { matrix alloy }\end{array}$ & $\begin{array}{c}\text { COF for silicon carbide based } \\
\text { aluminum metal matrix } \\
\text { composite }\end{array}$ \\
\hline Dry 10 N & 0.65 & 0.42 \\
Dry 20 N & 0.57 & 0.37 \\
Dry 30 N & 0.47 & 0.30 \\
Lubricated 10 N & 0.46 & 0.32 \\
Lubricated 20 N & 0.43 & 0.25 \\
Lubricated 30 N & 0.36 & 0.19 \\
\hline
\end{tabular}

Track diameter $=100 \mathrm{~mm}, N=600 \mathrm{rpm}$, sliding speeds $=3.14 \mathrm{~m} / \mathrm{sec}$, and $\Delta T$ $=600 \mathrm{sec}$.

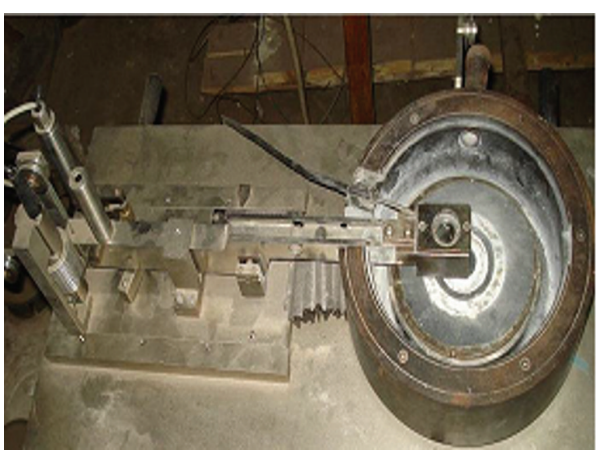

Figure 1: DUCOM Machine.

in terms of weight, weights of specimen before and after the experiment were taken.

The sliding speed of the test specimen is calculated by using the following formula:

$$
V=\frac{\pi * D * N}{60000}
$$

The following calculation is used to obtain wear rate:

$$
K_{0}=\frac{\Delta m}{\rho * F * d}
$$

\section{Results and Discussion}

3.1. Coefficient of Friction. The variations of coefficient of friction for aluminum matrix alloy (Al 7075) and composites under dry and lubricated condition at different normal loads and two sliding speeds (i.e., $3.14 \mathrm{~m} / \mathrm{s}$ and $3.77 \mathrm{~m} / \mathrm{s}$ ) have been shown in Tables 3 and 4, respectively. Table 3 shows that there is significant decrease in the value of coefficient of friction for composite compared with aluminum matrix alloy under dry and lubricated condition. Under dry condition, 30\%-55\% 
TABLE 4: Variation of coefficient of friction with load for aluminum matrix alloy and silicon carbide based aluminum metal matrix composite at $V=3.77 \mathrm{~m} / \mathrm{sec}$.

\begin{tabular}{lcc}
\hline $\begin{array}{l}\text { Sliding condition } \\
\text { \& load }\end{array}$ & $\begin{array}{c}\text { COF for } \\
\text { aluminum } \\
\text { matrix alloy }\end{array}$ & $\begin{array}{c}\text { COF for silicon carbide based } \\
\text { aluminum metal matrix } \\
\text { composite }\end{array}$ \\
\hline Dry 10 N & 0.72 & 0.56 \\
Dry 20 N & 0.63 & 0.43 \\
Dry 30 N & 0.50 & 0.35 \\
Lubricated 10 N & 0.58 & 0.44 \\
Lubricated 20 N & 0.47 & 0.32 \\
Lubricated 30 N & 0.37 & 0.25
\end{tabular}

Track diameter $=120 \mathrm{~mm}, N=600 \mathrm{rpm}$, sliding speeds $=3.77 \mathrm{~m} / \mathrm{sec}$, and $\Delta T$ $=600 \mathrm{sec}$.

reductions in value of coefficient of friction for load range $10 \mathrm{~N}-30 \mathrm{~N}$ have been observed; this is because of uniform mixing of silicon carbide with aluminum matrix alloy and results in excellent bond between matrix alloy and silicon carbide particle. These reinforced silicon carbide particles act as load bearing members as the loads increase and reduce the touch area between specimen and rotating disk's surfaces [1] which leads to lower coefficient of friction. Similar observations have been observed by other investees $[14,15]$.

However, under lubricated condition, the value of coefficient of friction reduced for both aluminum matrix alloy and composites compared with dry condition; this is because of thin lubricating film formation between specimen and rotating disk surface. This thin lubricating film contains lumps of particles and as temperature and normal loads increase these particles break into a small number of particles and reorient themselves along the sliding plane and this leads to lower coefficient of friction.

Table 4 shows variation of coefficient of friction at increased sliding distance for both aluminum matrix alloy and composites. As the sliding distance increases the value of coefficient of friction increases for both aluminum matrix alloy and composites because of temperature rise of rubbing surfaces for aluminum matrix alloy and reinforcement of silicon carbide into aluminum matrix alloys makes the matrix alloy plastically constrained and it can sustain high temperature compared with aluminum matrix alloy. Silicon carbide also protects the matrix alloy from severe contact with counter surface and leads to lower coefficient of friction. Similar observations have been made by other investees [16]. As sliding distance increases, the thin lubricating film between specimen and rotating disk surface may get thickened and be responsible for breakage of small particles from specimen and these broken particles may be clogged between the rubbing surfaces and this leads to higher coefficient of friction.

Figures 2 and 3 show the variation of coefficient of friction with increasing normal loads under dry and lubricating condition at sliding speeds $3.14 \mathrm{~m} / \mathrm{s}$ and $3.77 \mathrm{~m} / \mathrm{s}$, respectively. It has been observed that temperature rise is greater in case of unreinforced aluminum matrix alloys compared to those in composites irrespective of the applied load and surface conditions. The rise in temperature leads to frictional

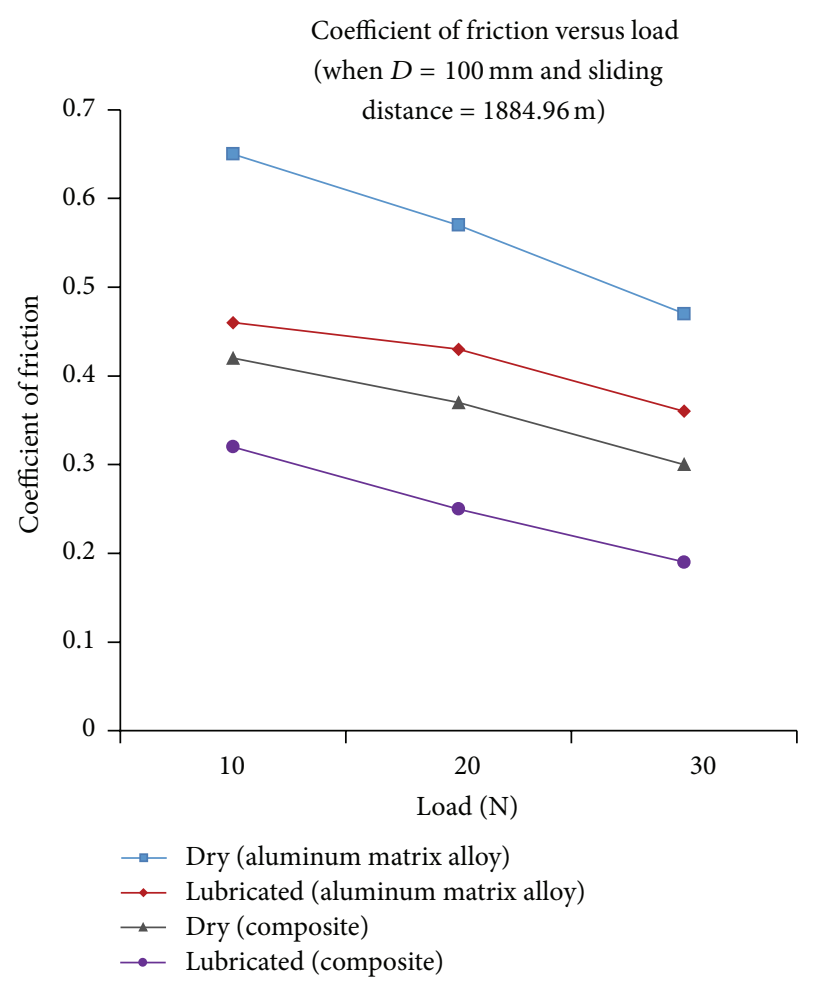

FIGURE 2: Variation of COF at $V=3.14 \mathrm{~m} / \mathrm{s}$.

heating in between the rubbing surfaces and this frictional heating is continuous because there is much less time for heat dissipation that causes higher coefficient of friction for aluminum matrix alloy compared to composites. Initially, aluminum alloys and composites particles are stronger and sharper which causes higher frictional heating and leads to higher coefficient of friction but as the time increases, there is increase in flow ability of material on specimen surface that leads to increase in slipping action and results in reduced frictional heating that leads to lower coefficient of friction at higher loads [1]. The composite shows lower coefficient of friction compared with aluminum matrix alloy because of presence of secondary phase of silicon carbide particles in aluminum matrix alloy which will restrict the flow of metal during sliding [17]. The uniform distribution of silicon carbide particle in aluminum matrix alloy would lead to sustaining higher loads with less plastic deformation and give us good load bearing capacity of composite at higher loads. The minimum values of coefficient of friction for both aluminum matrix alloy and composite have been observed at lower speeds; the same observations have been made by other investees [11].

\subsection{Wear Studies}

3.2.1. Weight Loss and Wear Rates. Effects of increasing loads (i.e., $10 \mathrm{~N}, 20 \mathrm{~N}$, and $30 \mathrm{~N}$ ) with sliding distance $1884.96 \mathrm{~m}$ (numerical values shown in Table 5) and $2262 \mathrm{~m}$ (numerical values in Table 6) on weight loss and wear rates for both aluminum matrix alloy and composites under dry and lubricated condition have been shown in Figures 4 and 5, respectively. 
TABLE 5: Variation of weight loss and wear rate for aluminum matrix alloy and silicon carbide based aluminum metal matrix composite when sliding speeds $=3.14 \mathrm{~m} / \mathrm{s}$.

\begin{tabular}{lcccc}
\hline $\begin{array}{l}\text { Sliding } \\
\begin{array}{l}\text { condition \& } \\
\text { load }\end{array}\end{array}$ & $\begin{array}{l}\text { (Weight loss })_{\text {alloy }}(\mathrm{mg}) \\
(\text { Wear rate })_{\text {alloy }}\left(\mathrm{mm}^{3} / \mathrm{N}-\mathrm{m}\right)\end{array}$ & $\begin{array}{l}(\text { Weight loss })_{\text {composite }}(\mathrm{mg}) \\
(\text { Wear rate })_{\text {composite }}(\mathrm{mm} / \mathrm{N}-\mathrm{m})\end{array}$ \\
\hline Dry 10 N & 3.8 & $4.662 \times 10^{-5}$ & 2.1 & $2.349 \times 10^{-5}$ \\
Dry 20 N & 8.6 & $5.275 \times 10^{-5}$ & 4.5 & $2.516 \times 10^{-5}$ \\
Dry 30 N & 15.2 & $6.216 \times 10^{-5}$ & 8.5 & $3.168 \times 10^{-5}$ \\
Lubricated 10 N & 3.0 & $3.680 \times 10^{-5}$ & 1.5 & $1.677 \times 10^{-5}$ \\
Lubricated 20 N & 6.5 & $3.987 \times 10^{-5}$ & 3.1 & $1.733 \times 10^{-5}$ \\
Lubricated 30 N & 13.2 & $5.398 \times 10^{-5}$ & 6.2 & $2.311 \times 10^{-5}$ \\
\hline
\end{tabular}

$\rho_{\text {alloy }}=4.324 \times 10^{-6} \mathrm{~kg} / \mathrm{mm}^{3}, \rho_{\text {composite }}=4.744 \times 10^{-6} \mathrm{~kg} / \mathrm{mm}^{3}$, sliding distance $(d)=1884.96 \mathrm{~m}$, and $\Delta T=600 \mathrm{sec}$.

TABLE 6: Variation of weight loss and wear rate for aluminum matrix alloy and silicon carbide based aluminum metal matrix composite when sliding speeds $=3.77 \mathrm{~m} / \mathrm{s}$.

\begin{tabular}{lcccc}
\hline $\begin{array}{l}\text { Sliding } \\
\text { condition \& } \\
\text { load }\end{array}$ & $\begin{array}{l}\text { (Weight loss })_{\text {alloy }}(\mathrm{mg}) \\
(\text { Wear rate })_{\text {alloy }}\left(\mathrm{mm}^{3} / \mathrm{N}-\mathrm{m}\right)\end{array}$ & $\begin{array}{l}(\text { Weight loss })_{\text {composite }}(\mathrm{mg}) \\
(\text { Wear rate })_{\text {composite }}(\mathrm{mm} / \mathrm{N}-\mathrm{m})\end{array}$ \\
\hline Dry 10 N & 6.7 & $6.85 \times 10^{-5}$ & 2.6 & $2.423 \times 10^{-5}$ \\
Dry $20 \mathrm{~N}$ & 13.7 & $7.003 \times 10^{-5}$ & 5.9 & $2.750 \times 10^{-5}$ \\
Dry 30 N & 22.4 & $7.634 \times 10^{-5}$ & 11.1 & $3.448 \times 10^{-5}$ \\
Lubricated 10 N & 4.9 & $5.009 \times 10^{-5}$ & 1.9 & $1.770 \times 10^{-5}$ \\
Lubricated 20 N & 11.2 & $5.725 \times 10^{-5}$ & 4.2 & $1.957 \times 10^{-5}$ \\
Lubricated 30 N & 17.5 & $5.964 \times 10^{-5}$ & 7.9 & $2.454 \times 10^{-5}$ \\
\hline
\end{tabular}

$\rho_{\text {alloy }}=4.324 \times 10^{-6} \mathrm{~kg} / \mathrm{mm}^{3}, \rho_{\text {composite }}=4.744 \times 10^{-6} \mathrm{~kg} / \mathrm{mm}^{3}$, sliding distance $(d)=2262 \mathrm{~m}$, and $\Delta T=600 \mathrm{sec}$.

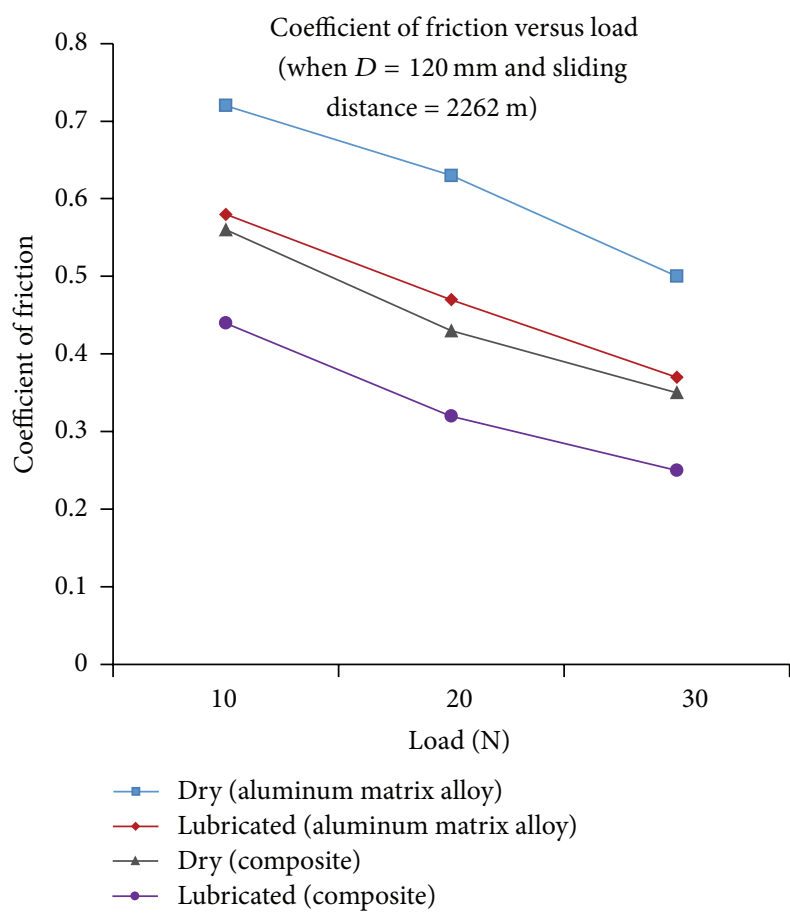

Figure 3: Variation of COF at $V=3.77 \mathrm{~m} / \mathrm{s}$.

Figure 4 shows the variation of weight loss and wear rates at sliding distance $1884.96 \mathrm{~m}$ with increasing loads. Mazahery and Shabani [18] observed that wear rates vary with normal rate and significantly it is low for composites compared to unreinforced alloys and it is indicative of Archard's law. In dry condition, rate of weight loss increases with increase in loads for both aluminum matrix alloy and composites because, with increasing loads, the rate of abrasion also increases and it will lead to detachment of metals from surfaces and leads to more loss of materials. But the rates of weight loss in composites are lower compared with aluminum matrix alloy because the presence of silicon carbide in aluminum matrix alloy controls the deformation and leads to less weight loss. The worn surfaces of composites are smoother and also shallower groove formations as the time increases which lead to higher wear resistance for composites compared with unreinforced aluminum matrix alloys [5]. As earlier we have seen that wear rates are directly proportional to weight loss, therefore wear rates will also be lower for composites compared with aluminum matrix alloy.

In lubricated condition, wear rates are lower compared with dry condition for both aluminum matrix alloy and composites because of thin lubricating film formation over rotating disk surfaces, and this thin lubricating film decreases the adhesion of small broken particles of aluminum matrix alloy and composites and leads to lower wear rates although it increases with increasing loads and if an applied load exceeds critical values, reinforced particle will break and loses its load carrying capacity properties and leads to more wear rates [5]. Critical loads basically mean that wear rates increase marginally with linear trends but suddenly these trends will 

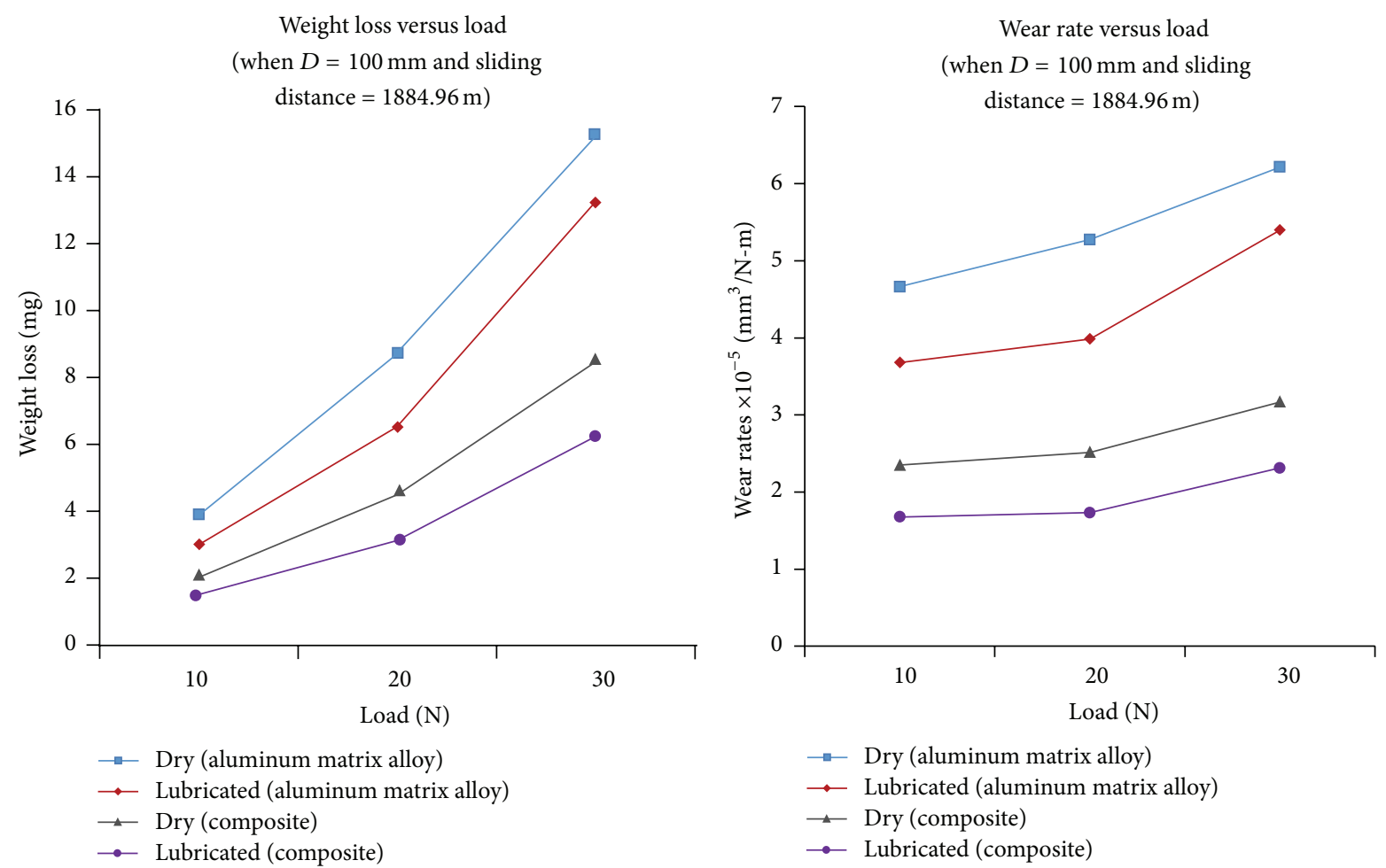

FIgURE 4: Variation of weight loss and wear rates at sliding distance $1884.96 \mathrm{~m}$ with increasing loads.
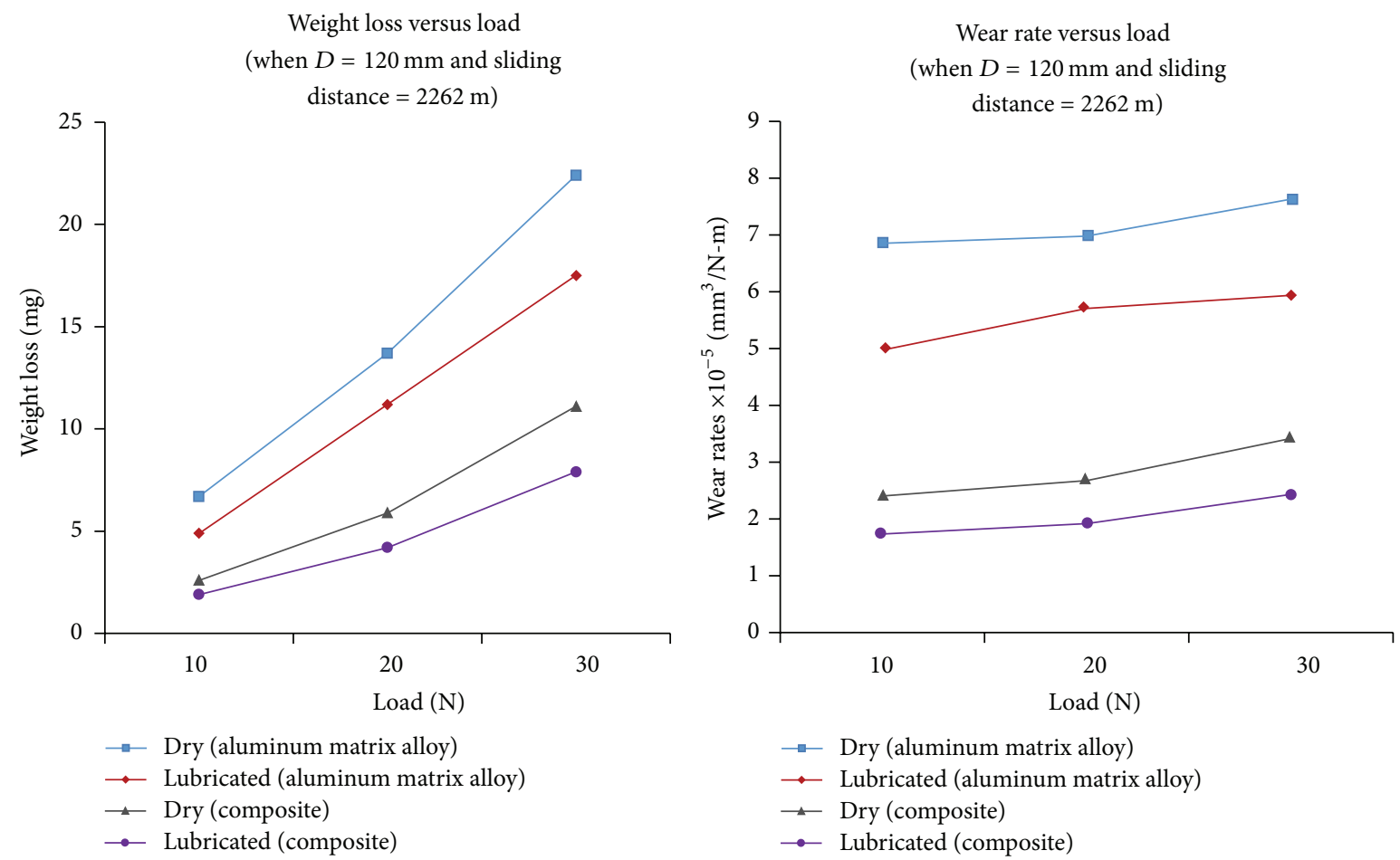

FIGURE 5: Variation of weight loss and wear rate at sliding distance $2262 \mathrm{~m}$ with increasing loads. 


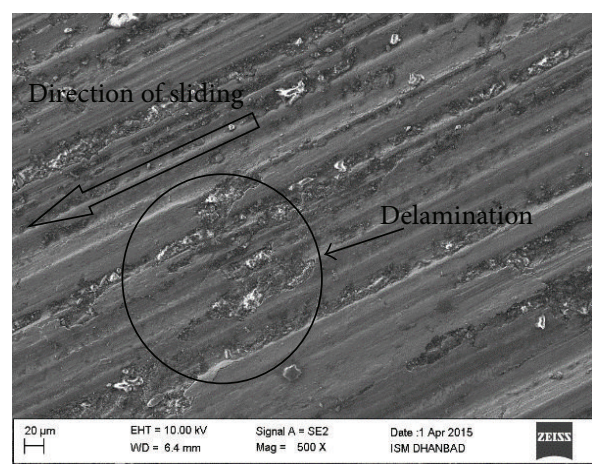

$10 \mathrm{~N}$ aluminum matrix alloy

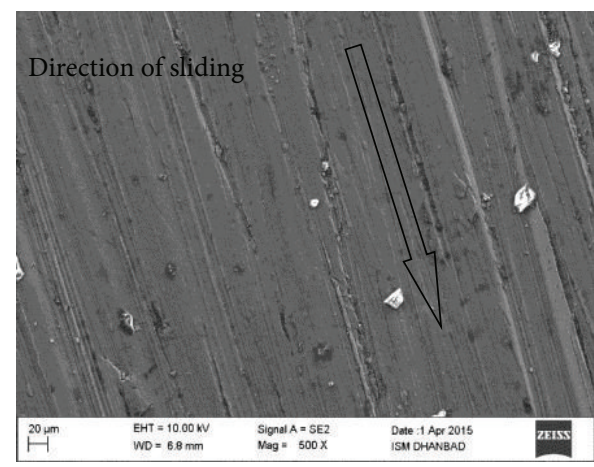

$20 \mathrm{~N}$ aluminum matrix alloy

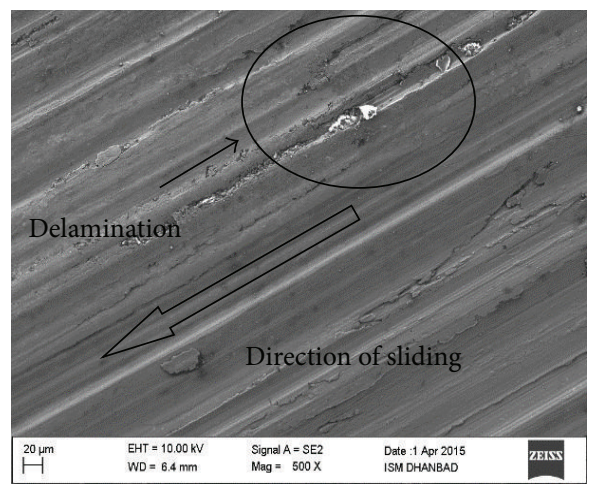

$30 \mathrm{~N}$ aluminum matrix alloy

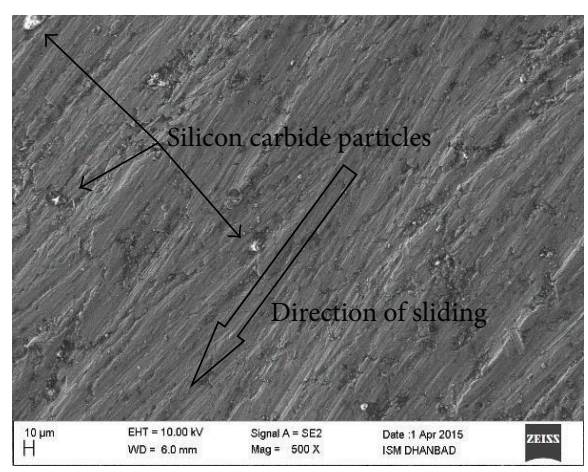

$10 \mathrm{~N}$ composite

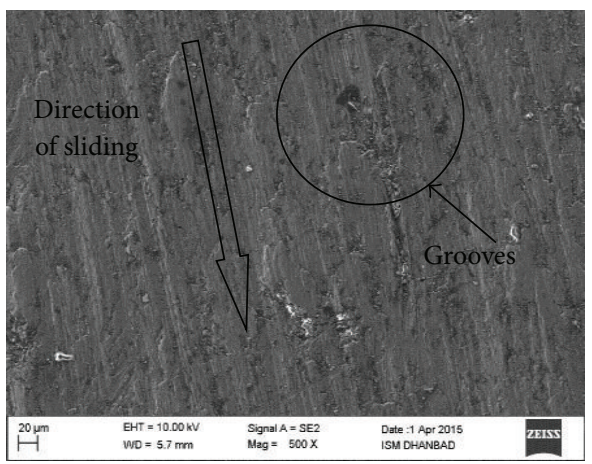

$20 \mathrm{~N}$ composite

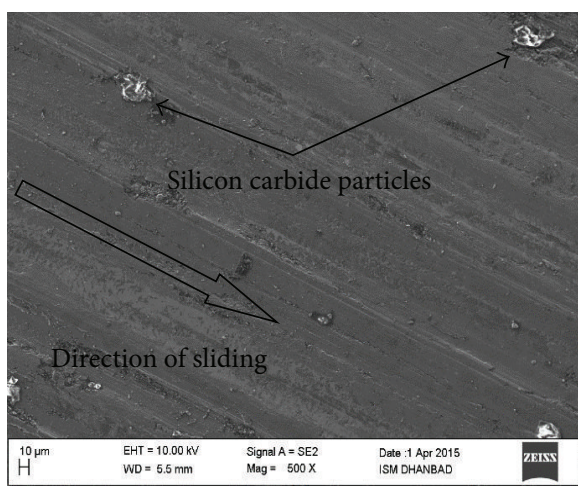

$30 \mathrm{~N}$ composite

FiguRE 6: FESEM of worn surfaces at different loads with sliding speeds $3.14 \mathrm{~m} / \mathrm{s}$ under dry condition.

not follow the loads up to which these trends that follow are known as critical loads.

Figure 5 shows the variation of weight loss and wear rates with increased sliding distance $2262 \mathrm{~m}$ with increasing loads. The increase of sliding distance leads to increase in weight loss and wear rates for both aluminum matrix alloy and composites because as sliding distance increases, the contact between rotating disk surface and sliding surface of specimen becomes more familiar with elapse of time; because of this the temperature between the rotating disk surface and sliding surface of specimen increases and leads to softening of materials and plastic state of materials occurs. Similar observations have been made by other investees $[19,20]$.
3.2.2. FESEM Analysis. FESEM micrographs of all worn surfaces for both aluminum matrix alloy and composites under dry and lubricated condition at sliding speeds $3.14 \mathrm{~m} / \mathrm{s}$ and $3.77 \mathrm{~m} / \mathrm{s}$ have been shown at magnification rate $(\times 500)$.

Figure 6 shows the FESEM analysis of all worn surfaces for both aluminum matrix alloy and composites at different loads with sliding speeds $3.14 \mathrm{~m} / \mathrm{s}$ under dry condition. It is clearly observed that, because of plastic flow of material, the wear rates for both aluminum matrix alloy and composites increase with increase of loads and severity of plastic flow increases at higher loads. At higher loads, the wear debris is mixture of fine and coarse size particles; this is because of breakdown of large size particles. As the load increases 


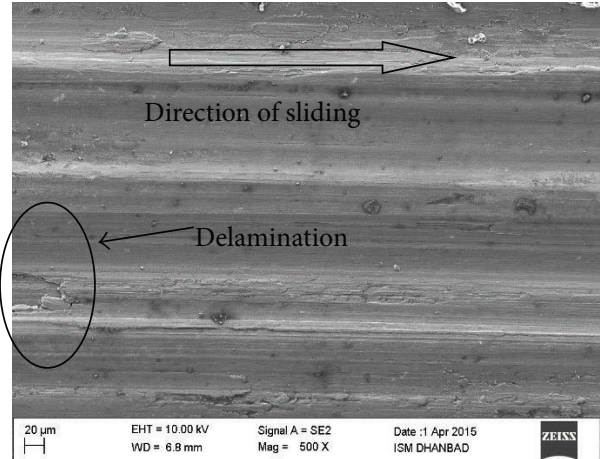

$10 \mathrm{~N}$ aluminum matrix alloy

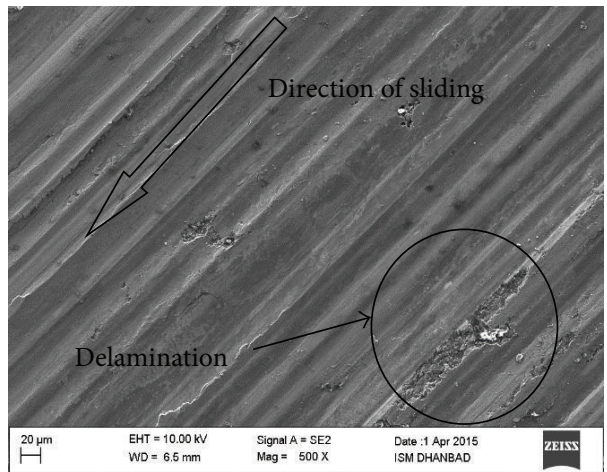

$20 \mathrm{~N}$ aluminum matrix alloy

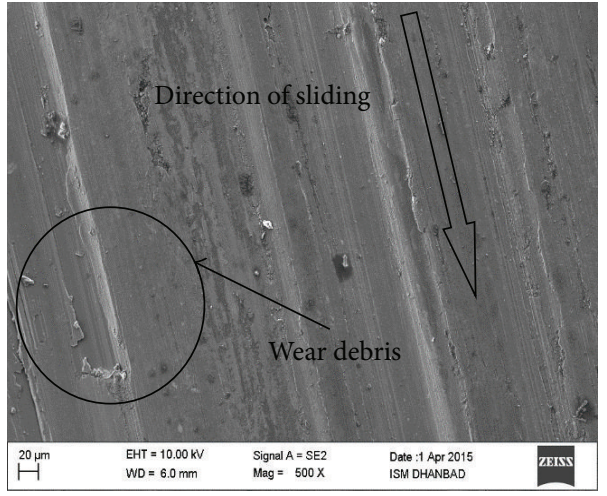

$30 \mathrm{~N}$ aluminum matrix alloy

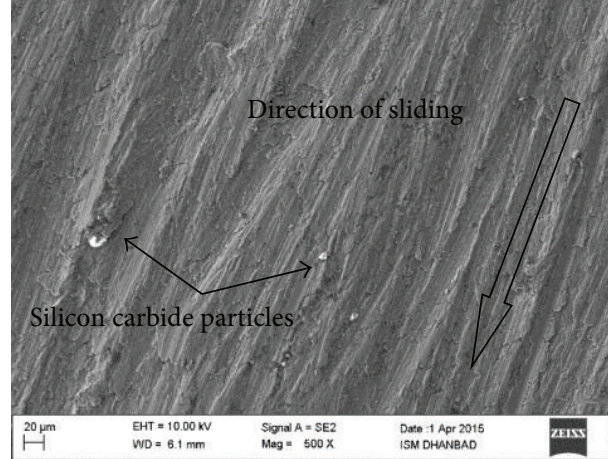

$10 \mathrm{~N}$ composite

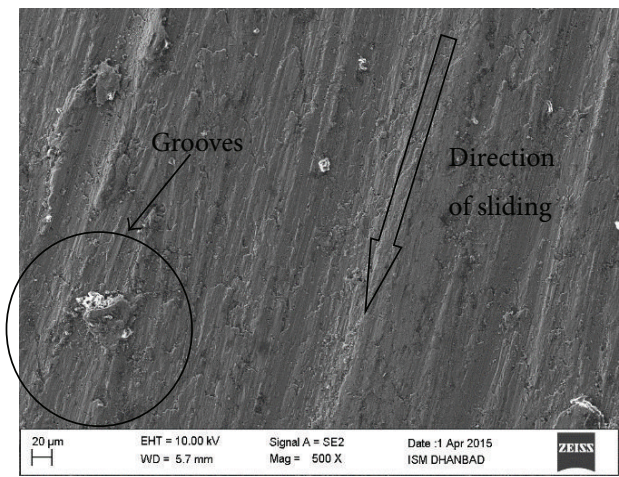

$20 \mathrm{~N}$ composite

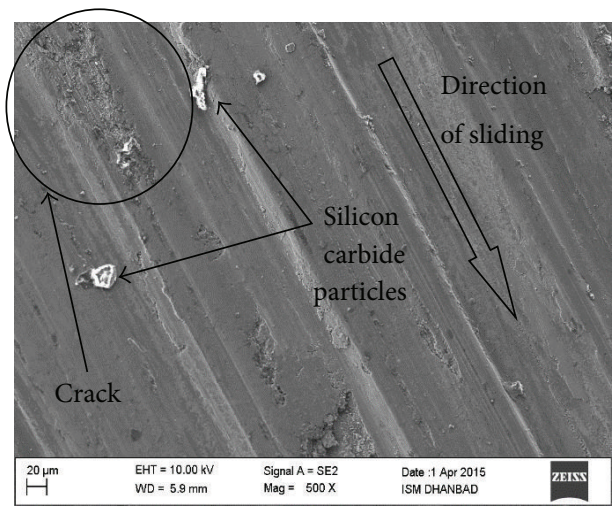

$30 \mathrm{~N}$ composite

FIGURE 7: FESEM of worn surfaces at different loads with sliding speeds $3.14 \mathrm{~m} / \mathrm{s}$ under lubricated condition.

the intersection between the sliding surface of specimen and rotating disk surface increases and leads to breakage of large particles into smaller number of particles. At lower loads, worn surfaces are smooth and grooves are small in size compared with higher loads; with increase in loads these grooves become severe and lead to formation of fracture spots. At these conditions reinforced particles cannot be in stable equilibrium and this leads to increase in wear rates.

Figure 7 shows the FESEM analysis of all worn surfaces for both aluminum matrix alloy and composites at different loads with sliding speeds $3.14 \mathrm{~m} / \mathrm{s}$ under lubricated condition. In lubricated condition lower wear rates have been observed compared with dry condition because of thin lubricating film formation between sliding surface of specimen and rotating disk surface and it decreases the ploughing action and leads to decrease in breakage of small particles from aluminum matrix alloy and composites; therefore, lower wear rates have been observed in lubricated condition compared with dry condition.

Figure 8 shows the FESEM analysis of all worn surfaces for both aluminum matrix alloy and composites at different loads with sliding speeds $3.77 \mathrm{~m} / \mathrm{s}$ under dry condition. As the sliding distance increases, there is gradual increase in wear rates for both aluminum matrix alloy and composites. The above results can be observed because of the following reason:

(i) With increase in sliding distance, the temperature at specimen interface increases and leads to softening the materials and plastic flow of materials. 


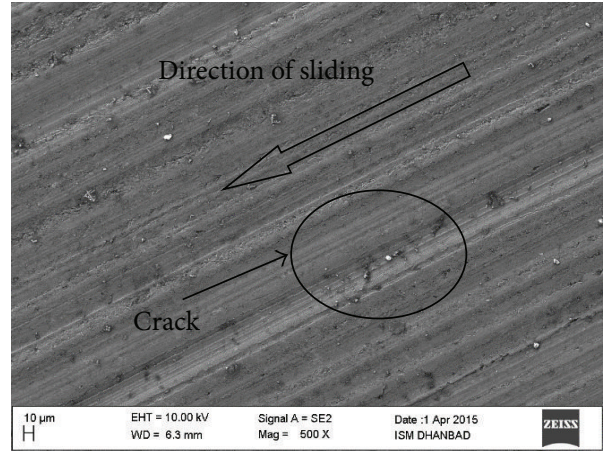

$10 \mathrm{~N}$ aluminum matrix alloy

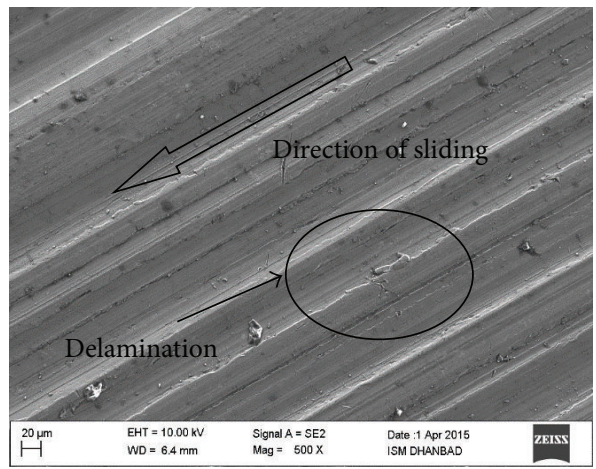

$20 \mathrm{~N}$ aluminum matrix alloy

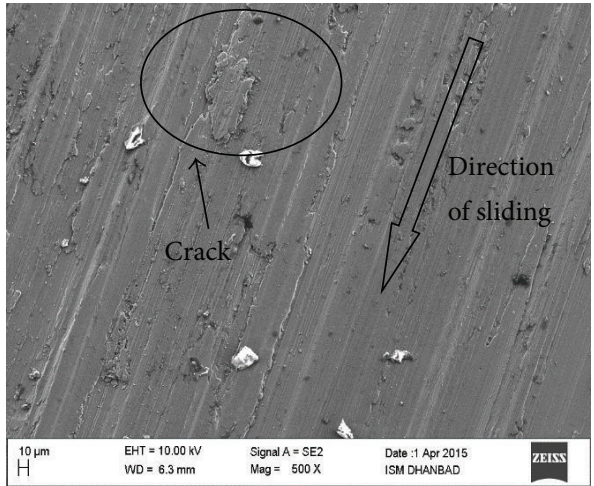

$30 \mathrm{~N}$ aluminum matrix alloy

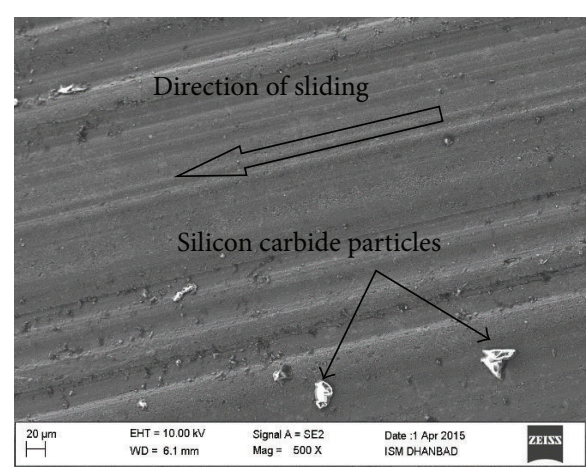

$10 \mathrm{~N}$ composite

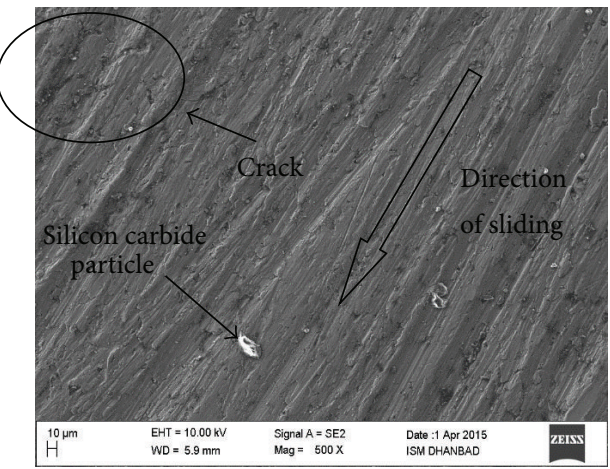

$20 \mathrm{~N}$ composite

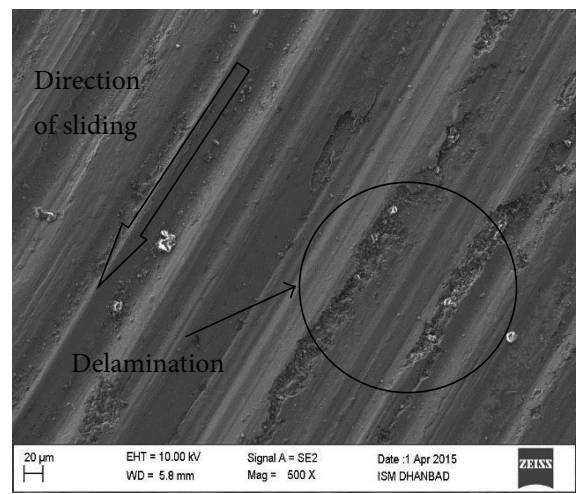

$30 \mathrm{~N}$ composite

FIGURE 8: FESEM of worn surfaces at different loads with sliding speeds $3.77 \mathrm{~m} / \mathrm{s}$ under dry condition.

(ii) With increase in sliding distance, the contact between sliding surface of specimen and rotating disk surface becomes intimate as time increases resulting in higher wear rates.

However, the wear rates are lower for composites compared with aluminum matrix alloy because some particles of silicon carbide break into small pieces and crushed as the disk rotates and act as abrasive medium. These powdered silicon carbide particles along with aluminum small particles made a layer which is called mechanically mixed layer (MML). These layers prevent the plastic flow and reduce the wear rates compared with aluminum matrix alloy although plastic flow of composites occurs at later stage.

Figure 9 shows the FESEM analysis of all worn surfaces for both aluminum matrix alloy and composites at different loads with sliding speeds $3.77 \mathrm{~m} / \mathrm{s}$ under lubricated condition. At higher sliding speeds, wear rates are lower in lubricated condition because of thin lubricating film formation and another mechanically mixed layer (MML) formation delays the plastic flow of material and leads to lower wear rates in lubricated condition compared with dry condition.

\section{Conclusions}

After observing the condition, that is, dry and oil lubricated condition of aluminum matrix alloy and silicon carbide based aluminum metal matrix composite, the following conclusion can be drawn:

(1) The values of coefficient of friction are found to be maximum in case of dry condition in matrix alloy 


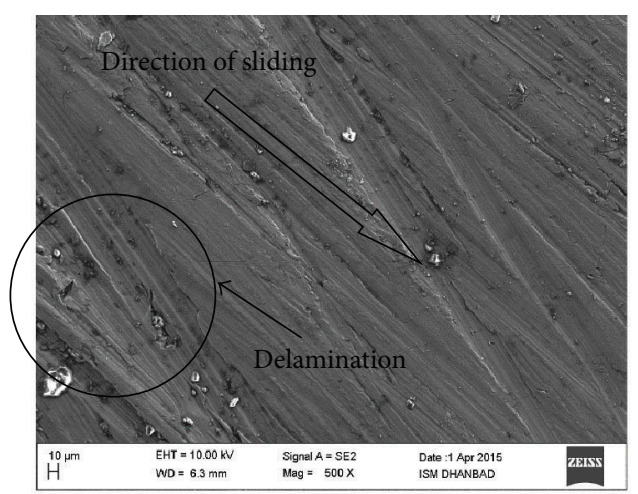

$10 \mathrm{~N}$ aluminum matrix alloy

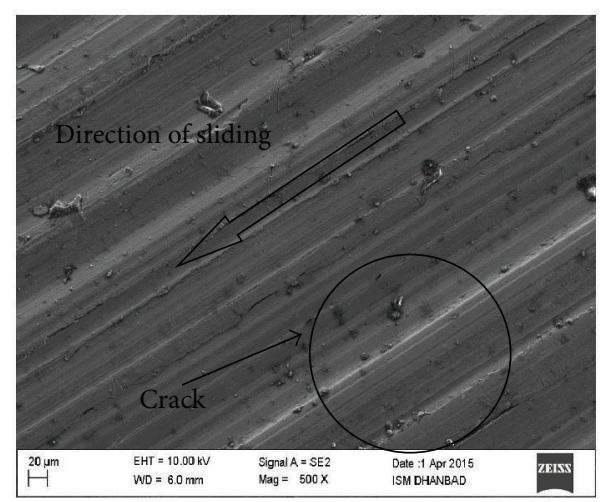

$20 \mathrm{~N}$ aluminum matrix alloy

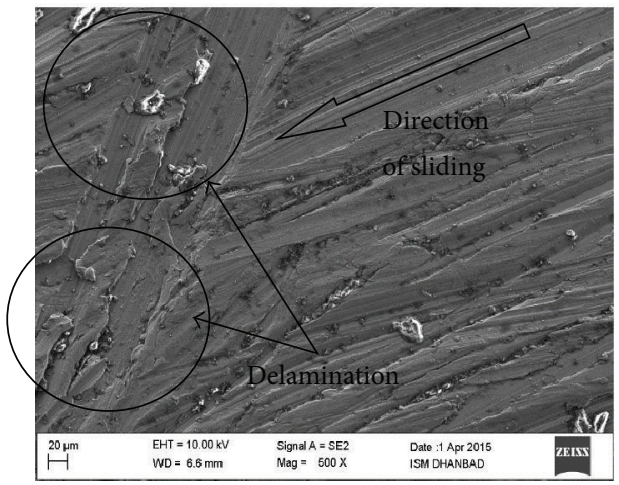

$30 \mathrm{~N}$ aluminum matrix alloy

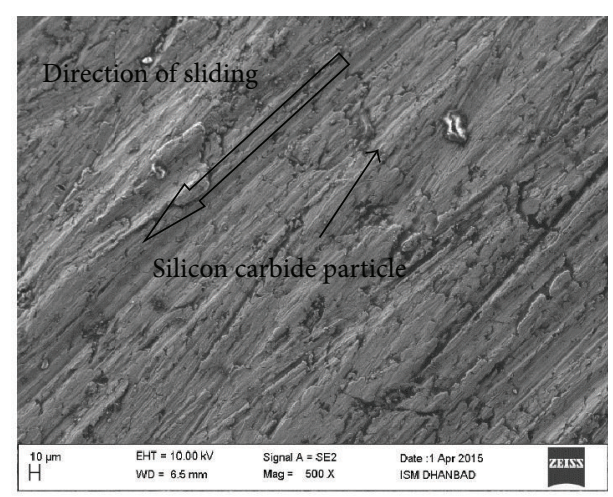

$10 \mathrm{~N}$ composite

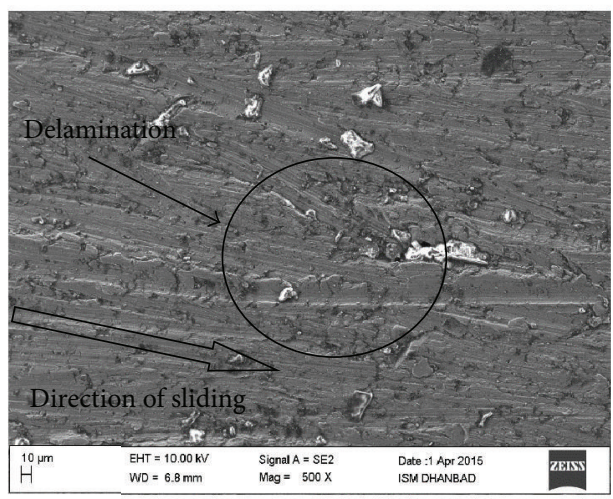

$20 \mathrm{~N}$ composite

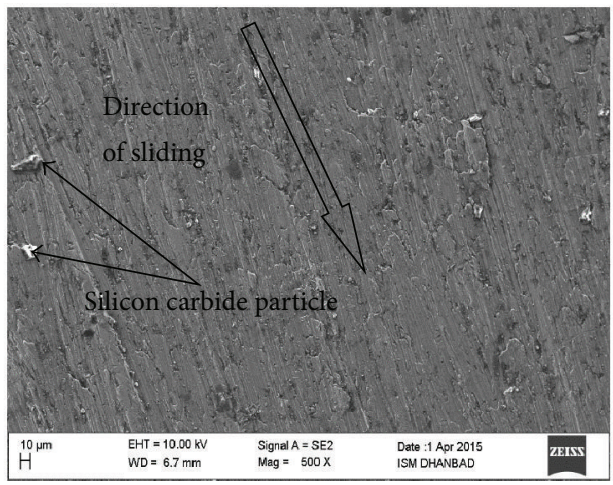

$30 \mathrm{~N}$ composite

FIGURE 9: FESEM of worn surfaces at different loads with sliding speeds $3.77 \mathrm{~m} / \mathrm{s}$ under lubricated condition.

at sliding speed $3.77 \mathrm{~m} / \mathrm{s}$ and minimum in case of lubricated condition in composite at sliding speed $3.14 \mathrm{~m} / \mathrm{s}$. The range of coefficient of friction lies from 0.19 to 0.72 .

(2) The values of coefficient of friction and wear rates are minimum for both aluminum matrix alloy and silicon carbide based aluminum metal matrix composites under lubricated condition compared with dry condition.

(3) As we increase normal load and sliding speed, the wear rate increases and it is found to be maximum in dry condition of matrix alloy at $30 \mathrm{~N}$.
(4) Uniform distribution of silicon carbide in aluminum matrix alloy reduces the values of coefficient of friction and wear rates for composites compared with aluminum matrix alloy under dry and lubricated condition which prolongs the life of composites for longer duration.

(5) The reinforcements of silicon carbide in aluminum matrix alloy significantly improve the strength of material in dry and lubricated condition and act as load bearing members as the loads and sliding speeds increase and give the best results in lubricated condition at low sliding speeds and loads. 
(6) From the above analysis and discussions we conclude that silicon carbide based aluminum metal matrix composite should be preferred for low speed applications as the same results are also observed by other researchers [21].

\section{Nomenclature}

$V: \quad$ Sliding speeds $(\mathrm{m} / \mathrm{sec})$

D: Diameter of track $(\mathrm{mm})$

$N$ : Rotating disk speed (rpm)

$F$ : $\quad$ Normal load (N)

$K_{0}$ : Wear rate $\left(\mathrm{mm}^{3} / \mathrm{N}-\mathrm{m}\right)$

$d$ : $\quad$ Sliding distance in meter

$\rho: \quad$ Density of specimen $\left(\mathrm{kg} / \mathrm{mm}^{3}\right)$

$\Delta m$ : Weight loss of specimen (mg).

\section{Competing Interests}

The authors declare that they have no competing interests.

\section{Acknowledgments}

The authors are grateful to the Advanced Composite Lab of Department of Mechanical Engineering of Indian School of Mines, Dhanbad, India, for providing them with the experimental support for carrying out the laboratory work.

\section{References}

[1] A. Mazahery and M. O. Shabani, "Study on microstructure and abrasive wear behavior of sintered Al matrix composites," Ceramics International, vol. 38, no. 5, pp. 4263-4269, 2012.

[2] C. G. E. Mangin, J. A. Isaacs, and J. P. Clark, "MMCs for automotive engine applications," JOM, vol. 48, no. 2, pp. 49-51, 1996.

[3] G. Straffelini, F. Bonollo, A. Molinari, and A. Tiziani, "Influence of matrix hardness on the dry sliding behaviour of $20 \mathrm{vol} . \%$ $\mathrm{Al}_{2} \mathrm{O}_{3}$-particulate-reinforced $6061 \mathrm{Al}$ metal matrix composite," Wear, vol. 211, no. 2, pp. 192-197, 1997.

[4] H.-S. Chu, K.-S. Liu, and J.-W. Yeh, "An in situ composite of $\mathrm{Al}$ (graphite, $\mathrm{Al} 4 \mathrm{C} 3$ ) produced by reciprocating extrusion," Materials Science and Engineering A, vol. 277, no. 1-2, pp. 25-32, 2000.

[5] A. Mazahery and M. O. Shabani, "The effect of primary and secondary processing on the abrasive wear properties of compocast aluminum 6061 alloy matrix composites," Protection of Metals and Physical Chemistry of Surfaces, vol. 50, no. 6, pp. 817-824, 2014.

[6] S. C. Lim, M. Gupta, L. Ren, and J. K. M. Kwok, "The tribological properties of $\mathrm{Al}-\mathrm{Cu} / \mathrm{SiCp}$ metal-matrix composites fabricated using the rheocasting technique," Journal of Materials Processing Technology, vol. 80-90, pp. 591-596, 1999.

[7] C. García-Cordovilla, J. Narciso, and E. Louis, "Abrasive wear resistance of aluminium alloy/ceramic particulate composites," Wear, vol. 192, no. 1-2, pp. 170-177, 1996.

[8] W. Aiguo and H. J. Rack, "Abrasive wear of silicon carbide particulate- and whisker-reinforced 7091 aluminum matrix composites," Wear, vol. 146, no. 2, pp. 337-348, 1991.
[9] P. Rodrigo, M. Campo, B. Torres, M. D. Escalera, E. Otero, and J. Rams, "Microstructure and wear resistance of Al-SiC composites coatings on ZE41 magnesium alloy," Applied Surface Science, vol. 255, no. 22, pp. 9174-9181, 2009.

[10] Y. Sahin and V. Kilicli, "Abrasive wear behaviour of SiCp/Al alloy composite in comparison with ausferritic ductile iron," Wear, vol. 271, no. 11-12, pp. 2766-2774, 2011.

[11] J. K. M. Kwok and S. C. Lim, "High-speed tribological properties of some $\mathrm{Al} / \mathrm{SiCp}$ composites. I. Frictional and wear-rate characteristics," Composites Science and Technology, vol. 59, no. 1, pp. 55-63, 1999.

[12] A. Mazahery and M. O. Shabani, "Existence of good bonding between coated $\mathrm{B} 4 \mathrm{C}$ reinforcement and al matrix via semisolid techniques: enhancement of wear resistance and mechanical properties," Tribology Transactions, vol. 56, no. 3, pp. 342-348, 2013.

[13] M. O. Shabani and A. Mazahery, "Application of finite element model and artificial neural network in characterization of al matrix nanocomposites using various training algorithms," Metallurgical and Materials Transactions A, vol. 43, no. 6, pp. 2158-2165, 2012.

[14] Z. F. Zhang, L. C. Zhang, and Y.-W. Mai, "Particle effects on friction and wear of aluminium matrix composites," Journal of Materials Science, vol. 30, no. 23, pp. 5999-6004, 1995.

[15] S. Wilson and A. T. Alpas, "Wear mechanism maps for metal matrix composites," Wear, vol. 212, no. 1, pp. 41-49, 1997.

[16] F. Rana and D. M. Stefanescu, "Friction properties of Al-1.5\% $\mathrm{Mg} / \mathrm{SiC}$ particulate metal-matrix composites," Metallurgical and Materials Transactions A, vol. 20, pp. 1564-1566, 1989.

[17] S. Kumar and V. Balasubramanian, "Effect of reinforcement size and volume fraction on the abrasive wear behaviour of AA7075 $\mathrm{Al} / \mathrm{SiCp} \mathrm{P} / \mathrm{M}$ composites-a statistical analysis," Tribology International, vol. 43, no. 1-2, pp. 414-422, 2010.

[18] A. Mazahery and M. O. Shabani, "Mechanical properties of squeeze-cast $\mathrm{A} 356$ composites reinforced with $\mathrm{B}_{4} \mathrm{C}$ particulates," Journal of Materials Engineering and Performance, vol. 21, no. 2, pp. 247-252, 2012.

[19] I. M. Hutchings, "Tribological properties of metal matrix composites," Materials Science and Technology, vol. 10, no. 6, pp. 513-517, 1994.

[20] T. Ma, H. Yamaura, D. A. Koss, and R. C. Voigt, "Dry sliding wear behavior of cast SiC-reinforced Al MMCs," Materials Science and Engineering A, vol. 360, no. 1-2, pp. 116-125, 2003.

[21] K. R. Brown, M. S. Venie, and R. A. Woods, "The increasing use of aluminum in automotive applications," $J O M$, vol. 47, no. 7, pp. $20-23,1995$. 

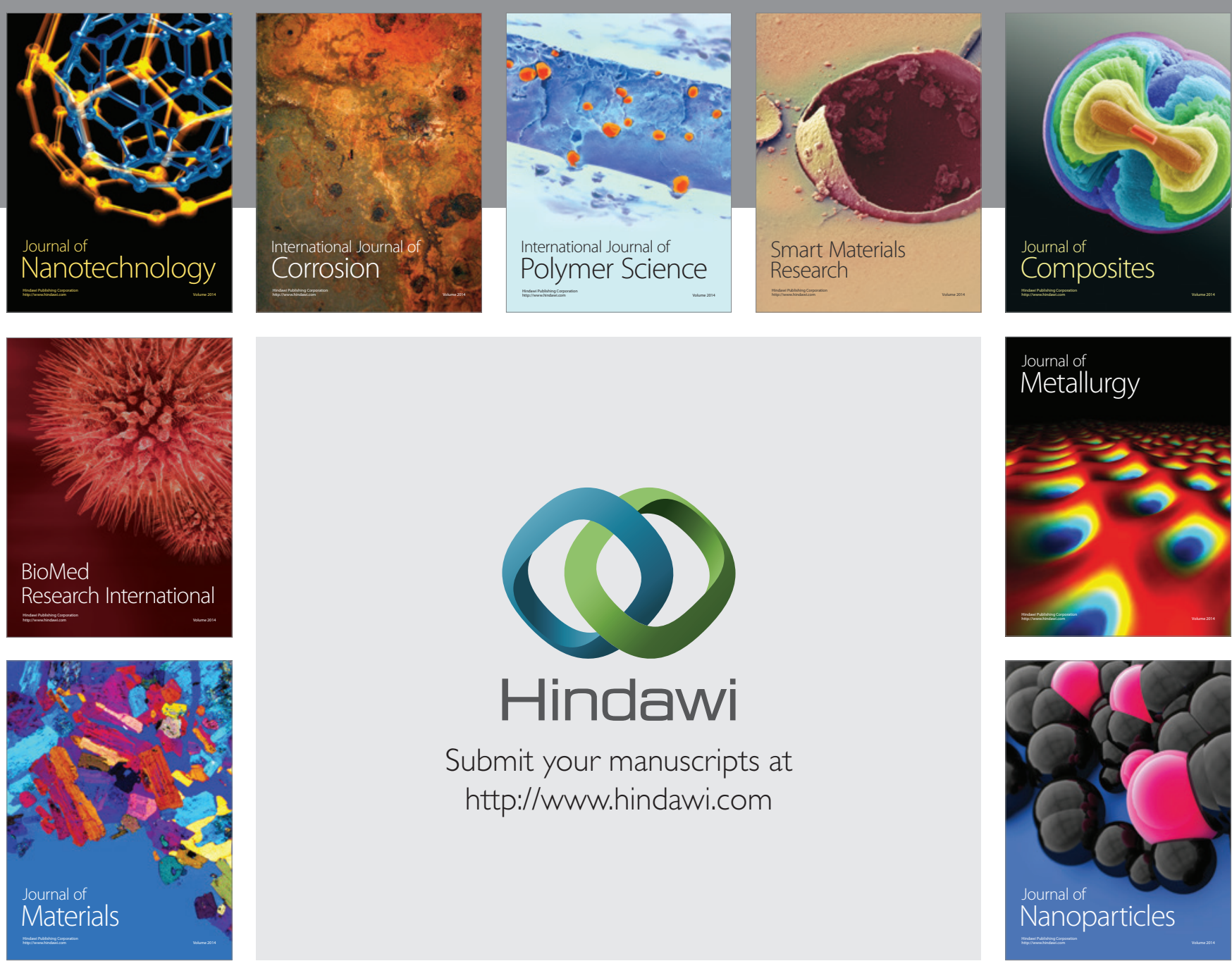

\section{Hindawi}

Submit your manuscripts at

http://www.hindawi.com

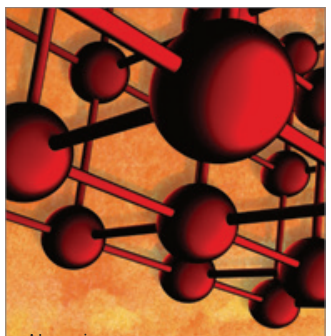

Materials Science and Engineering
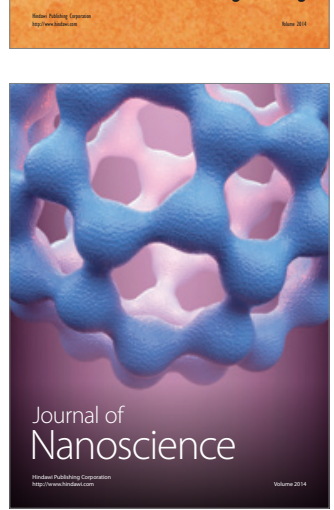
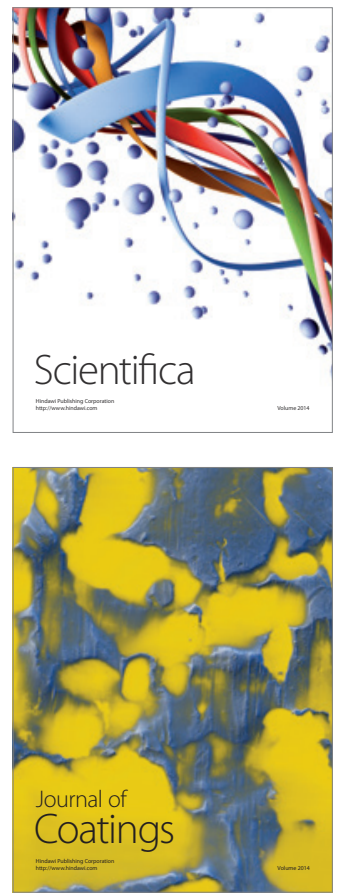
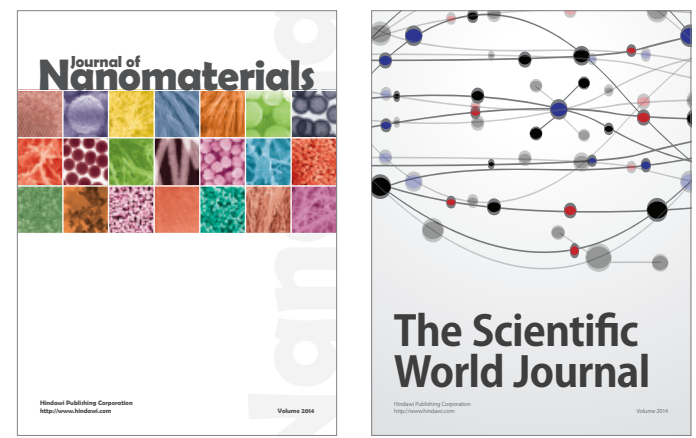

The Scientific World Journal
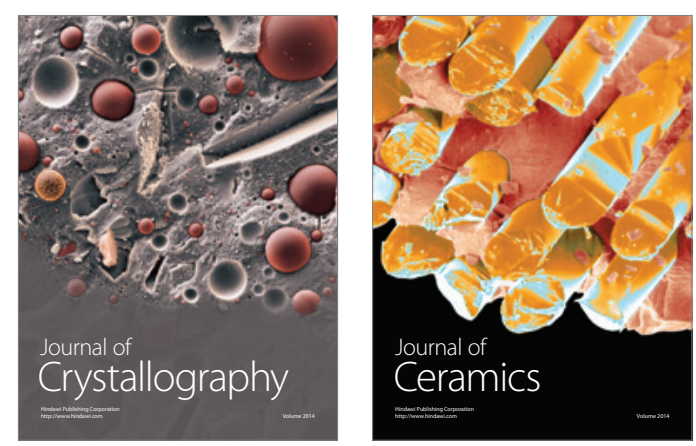
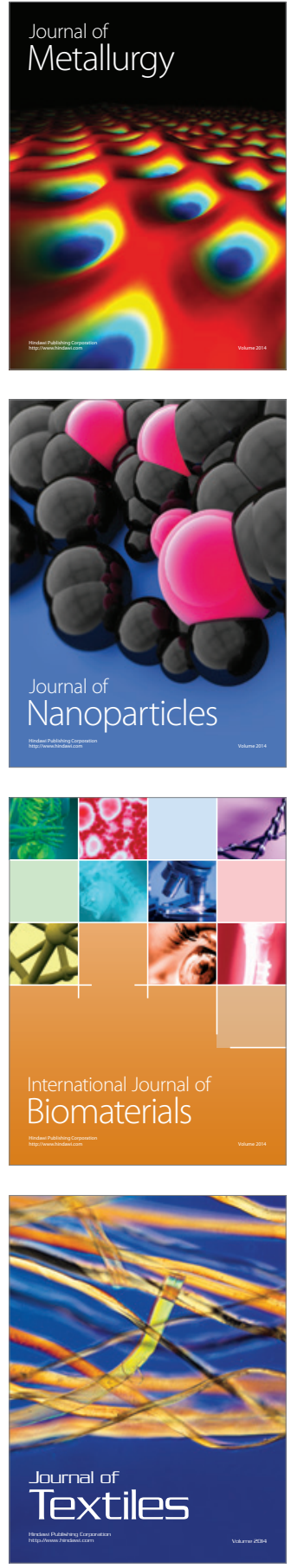